\title{
Development of an Efficient Transient Gene Expression Assay Based on Tobacco ((Nicotiana tabacum var. Xanthi) Male Gametophytes
}

\author{
M. A. Y. Akhond ${ }^{1}$ and G. C. Machray ${ }^{2}$ \\ Scottish Crop Research Institute, Invergowrie, Dundee, DD2 5DA, Scotland, UK. \\ Key words: Biolistic, GFP, Microspore, Tobacco, Nicotiana tabacum, Transformation
}

\begin{abstract}
Optimization of direct DNA delivery into tobacco ((Nicotiana tabacum var. Xanthi) male gametophytes was devised together with development of an efficient transient expression system to study gene expression under controlled conditions. Use of a GFP gene driven by strong promoter and enhancer sequences allowed an efficient non-lethal transient gene expression assay with an overall transient gene expression frequency of $>4 \%$ for uninucleate microspores and between 10 and $20 \%$ for binucleate pollen. The technique demonstrated its suitability for analysis of developmental stage-specific gene expression. The assay allowed observation of real-time transgene expression during microspore maturation proving useful for in vitro pollen selection. We have also used this protocol to determine the recombination potential of tobacco male gametic cells by assessing the frequency of extra-chromosomal homologous recombination events after co-delivery of two loss-of-function GFP genes. No increase of extrachromosomal recombination was observed in assays for transient transformation.
\end{abstract}

\section{Introduction}

The microspores of higher plants, isolated and cultured under controlled conditions, represent a unique experimental material in the form of a large population of autonomous, almost synchronously developing haploid cells. On further in vitro culture in an appropriate medium, microspores can develop into fertile mature pollen grains capable of pollination in vivo (Benito Moreno et al. 1988, Stauffer et al. 1991). The 'gametophytic pathway', closely resembles that of the natural pollen development in vivo. Thus in vitro pollen maturation is an attractive system to study developmental processes during gametogenesis, pollen selection, plant transformation and the rescue of sterile or selfincompatible pollen for self-pollination (Touraev and Heberle-Bors 1999).

${ }^{1}$ Correspondence: Biotechnology Division, Bangladesh Agricultural Research Institute, Joydebpur, Gazipur-1701, Bangladesh. E-mail: <a_akhond@hotmail.com>. ${ }^{2}$ Scottish Agricultural Science Agency, Roddinglaw Road, Edinburgh, EH12 9FJ, Scotland, UK. 
As the pathway of pollen development appears to be well conserved among angiosperms, it was suggested that many basic developmental processes and the genes controlling them are also shared (Twell 1994). Study of pollen development and function in 28 different plant species has led to the characterization of more than 150 microspore- or pollen-expressed genes, preferentially activated at particular stages of development (Twell 2002). There are two broadly-defined groups of pollen genes: the 'early genes' activated soon after meiosis and the 'late genes' which are activated after microspore mitosis (Mascarenhas 1990). Study of pollen-specific gene expression is important for the understanding of the mechanisms associated with pollination, fertilization, selfincompatibility and male-sterility as the concerned genes encode proteins thought or known to be involved in pollen development, pollen germination and pollen tube growth, as well as in interaction with the stigma, the transmitting tissue or the female gametophyte (Becker et al. 2003). It is suggested that products of some of the early genes may participate in cell wall loosening associated with pollen expansion after microspore mitosis and that the products of the late genes may play a role in cell expansion during pollen germination (Hrubá et al. 2005).

Late pollen genes are also associated with the production of major pollen allergens (Alché et al. 2004). It would be useful to develop a system that will allow study of these sequentially expressed genes in the gametophyte. Recently, two groups have found large overlap of the pollen transcriptome with that of the sporophyte in Arabidopsis (Becker et al. 2003, Honys and Twell 2003), signifying the applicability of a system based on the male gametophyte to the study other fundamental mechanisms of plant cell and developmental biology.

The production of stable transgenics is a well-established method for the characterization of gene function. However, this approach is time consuming and slow. Alternatively, a fast and convenient way of studying gametophytic gene expression is their transient expression after direct delivery into different developmental stages of the male gametophyte. Gene expression after biolistic transformation has been shown to resemble pollen-specific expression in planta (Schreiber and Dresselhaus 2003, Bate and Twell 1998, Eyal et al. 1995, Hamilton et al. 1992, Twell et al. 1989). Earlier a very low frequency of transient expression ( 0.1\% using a GUS gene) was reported (Twell et al. 1989). More recently, Barinova et al. (2002) observed 0.01 - 0.2\% transient expression for GFP, $5.0-7.0 \%$ for dsRFP and $5.0-7.0 \%$ for GUS in tobacco and Antirrhinum male gametic cells. Later, up to $21 \%$ transient expression of the hygromycin resistance gene, aph(4) in bombarded tobacco microspores after in vitro maturation and their germination was reported by Aziz and Machray 2003. 
Although both stable and transient expression can be used efficiently to study gene expression, the most precise manipulations of gene function can only be done through targeted gene modifications. Gene targeting is well established in lower eukaryotes like yeast and in the moss, Physcomitrella patens, where exogenous DNA integrates into the genome by homologous recombination (HR) (Schaefer and Zrÿd 1997). It is applicable to higher plant diploid tissues only under a powerful negative selection system capable of detecting rare HR events (Terada et al. 2002). The rate of HR in P. patens comprising, the haploid cells has been reported to be between 4 and $95 \%$ (Schaefer 2001) compared to from $10^{-3}$ to $10^{-6}$ in flowering plants (Hanin et al. 2001). Based on the observations on $P$. patens and lower eukaryotic cells, Schaefer and Zrÿd (1997) suggested a possible correlation between efficient gene targeting and haplophase in eukaryotes.

Here we describe the biolistic DNA delivery into tobacco male gametophytes using the non-lethal GFP reporter gene for the development of an efficient transient gene expression assay. Male gametophytes can be considered as the representatives of the haploid phase in the life cycle of higher plants. Using this high level of transient expression assay, we have also examined their recombination potential by assessing the frequency of extra-chromosomal HR events after co-delivery of two loss-of-function GFP genes into tobacco male gametic cells.

\section{Materials and Methods}

Tobacco (Nicotiana tabacum var. Xanthi) plants were grown in the glasshouse, under ambient conditions and supplemental lighting, and in a controlled environment growth room at $25^{\circ} \mathrm{C}$ and $70 \%$ humidity. Developmental stages of the microspores were determined using DAPI staining (Vergne et al. 1987). Stained microspores were observed under an epifluorescence microscope (Olympus BH2) with Ultra-Violet excitation filter U (UG-1) and barrier filter L-435. Based on microscopic observations, the developmental stages of microspores were correlated with bud length. Media preparation and microspore isolation were done essentially as described by Touraev and Heberle-Bors (1999) with some modifications. All media were filter-sterilised and stored at $4^{\circ} \mathrm{C}$ in the dark. The temperature of the media was allowed to equilibrate to room temperature $\left(23-25^{\circ} \mathrm{C}\right)$ prior to use. Microspores were isolated from five flower buds in B medium and the pellet re-suspended in $5 \mathrm{ml}$ of T1 medium. One $\mathrm{ml}$ aliquots of this suspension (approximately $2.5 \times 10^{5}$ microspores, i.e. the equivalent of one flower bud) were each distributed into a $30 \mathrm{ml}$ clear plastic Petri dish with triple vent (BIBBY Sterilin) sealed with Nescofilm. The plates were kept in an incubator for the indicated time and temperature in the dark for 
maturation. After the maturation period, $1 \mathrm{ml} \mathrm{P}$ medium was added to each of the cultures to induce dehydration of the microspores. After one day, another $\mathrm{ml}$ of $\mathrm{P}$ medium was added to the cultures and the cultures were incubated under the same conditions for another day. Observations were taken from sealed Petri dishes with an inverted microscope to check the progression of maturity over the culture period. The percentage of matured pollen in total microspores cultured was calculated by counting 200 - 500 cells from each of at least three different culture plates. Maturation of the microspores into pollen grains was verified by microscopic observation and their viability was tested by staining with FDA. The stock was diluted 1 : 50 with medium $\mathrm{P}$ and one drop was added to in vitro matured pollen grains, viewed after 5 min under an epifluorescence microscope, Olympus BH2 using excitation filter V (BP-405) and barrier filter Y-475. Later, their viability was also confirmed by culture in vitro in PEG8000 pollen germination medium.

Vector construction: Plasmid pRTL2mGFP5-ER contains the gene mGFP5-ER (U87974.1), a codon-optimized stable version of the green fluorescent protein (GFP) gene (Haseloff et al. 1997, Siemering et al. 1996) with a CaMV 35S promoter having dual enhancer, a leader sequence (for increased expression) from TEV, a C-terminal HDEL amino acid sequence and the $35 \mathrm{~S}$ poly(A) signal from CaMV. Two other plasmid constructs M1 and M2 having two mutant versions of the gene were made using site-directed mutagenesis (QuickChange ${ }^{\mathrm{TM}}$ Site-Directed Mutagenesis Kit, Stratagene). Three consecutive stop codons were created at the beginning (version M1) and near the end (version M2) of the gene (Fig. 1) by changing three nucleotides in each and the mutations confirmed by DNA sequencing. The original plasmid pRTL2mGFP5-ER and the two mutant versions of it, pRTL2M1mGFP5-ER and pRTL2M2mGFP5-ER, respectively, were transformed into E. coli XL1-Blue cells from which plasmid DNA was prepared.

In vitro assays for GFP activity in tobacco protoplasts: To check the functionality of proteins coded by the constructs, tobacco (Nicotiana tabacum var. Xanthi) protoplasts were transfected with the original pRTL2mGFP5-ER plasmid and the two mutant versions and, after an overnight culture in the dark at $25^{\circ} \mathrm{C}$, RNA extracted as described by Simpson et al. (1996). To detect expression from the constructs, RT-PCR was done using two $g f p$ sequence-specific primers (0391F: 5'CCC TTA AAT TTA TTT GCA CTA C-3' and 0392: 5'-CCA TAA GAG AAA GTA GTG AC-3') according to Simpson et al. (2000). Labelled RT-PCR products were separated on a $4 \%$ polyacrylamide denaturing gel on an ABI 377 DNA analyser. Expression of GFP protein was monitored under a fluorescence microscope (Olympus BH2, excitation filter BP-490, and barrier filter O-515).

Biolistic $^{\circledR}$ transformation of microspores: DNA was delivered into microspores using a PDS-1000/He Biolistic ${ }^{\mathrm{TM}}$ Particle Delivery System (BIO-RAD). Basic 
bombardment parameters were as described by Aziz and Machray (2003). The gap distance between rupture disk retaining cap and microcarrier launch assembly was maintained at $11 \mathrm{~cm}$ and 900 psi rupture disks were used. Chamber vacuum was kept at $28 \mathrm{~mm}$ of $\mathrm{Hg}$.

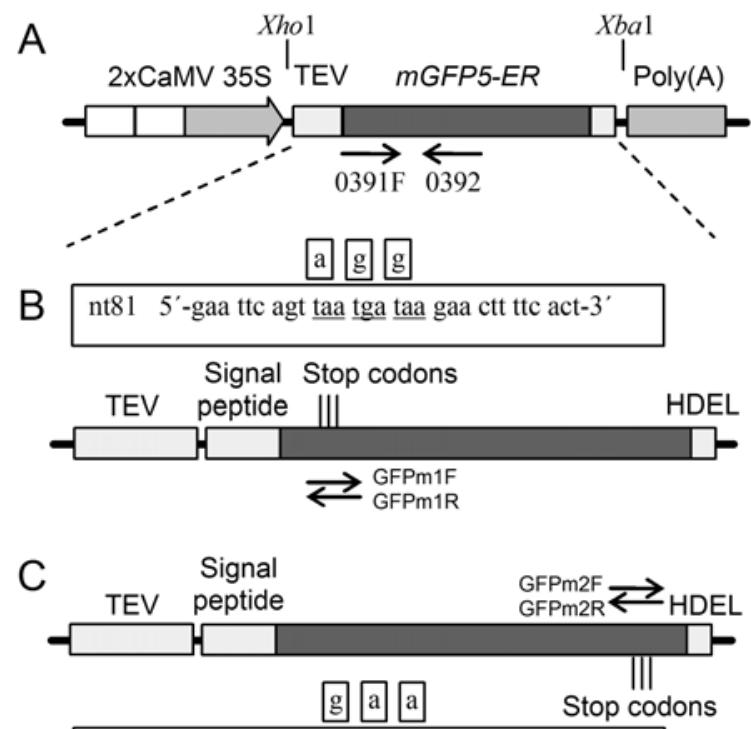

nt711 $5^{\prime}$-gat ccc aac taa tag tga gac cac atg gtc-3'

Fig. 1. Schematic representation of the reporter gene cassettes used for bombardment (not to scale). Portion of pRTL2 plasmid containing the mGFP5-ER gene driven by a CaMV 35S promoter with dual (2x) enhancer and CaMV Poly(A) terminator sequence (A); mutant versions of the geneM1mGFP5-ER (B) and M2mGFP5-ER (C). CaMV 35S- promoter; Poly(A)-CaMV poly(A) terminator sequence. Wild type nucleotides are shown in small boxes above the mutated sequences where stop codons were created. $m$ GFP5-ER- bases 1 to 818/CDS 21 to 812 (Accession: U87974.1) includes, TEV- leader sequence from Tobacco Etch Virus, Signal peptide and HDEL- sequences for ER localisation (Hasseloff et al. 1997). Respective primer positions for amplification and sequencing are shown with arrows.

Assay for transient mGFP5-ER expression in microspores: After in vitro maturation of the bombarded microspores, they were analyzed for normal development and for the transient expression of the transgene. Observations were taken under a fluorescence microscope (Olympus BH2, excitation filter BP490, and barrier filter O-515) once each day after bombardment with plasmid pRTL2mGFP5-ER and the two mutant versions along with non-bombarded control cultures for the expression of GFP. Observations were also taken after germination in the medium PEG8000. For the confirmation and localization of the $m G F P 5-E R$ expression, observations were taken with a Leica SP2 Laser Scanning Confocal Microscope (LSCM) using 488nm excitation and 502-520nm emission wavelengths. To ensure the homogeneity of the cultured cells, contents 
of separate culture plates were pooled together and aliquots were taken for further analysis and microscopic observation from at least three fields of view. Alternatively, observations were taken from at least three different plates.

\section{Results and Discussion}

Microspore isolation and culture: The basic protocol for microspore isolation and culture was based on that reported by Touraev and Heberle-Bors (1999) but modified to make the procedure simpler and more efficient. Reports of in vitro maturation of tobacco microspores are limited in number and from only a few laboratories (Kyo and Harada 1986, Touraev and Heberle-Bors 1999, Tupý et al. 1991). The aim of the present study was to develop an optimized protocol for in vitro maturation of tobacco gametic cells isolated before and after the first mitotic division. This required the optimization of the existing in vitro maturation protocol for isolated late-uninucleate microspores and its adaptation for the culture of early-binucleate pollen, allowing the transient expression study of 'early' and 'late' pollen genes.

Table 1. Germination of pollen grains matured from late uni- and early bi-nucleate microspores under different culture conditions.

\begin{tabular}{lcccc}
\hline $\begin{array}{l}\text { Developmental } \\
\text { stage }\end{array}$ & $\begin{array}{c}\text { Culture } \\
\text { temperature } \\
\left({ }^{\circ} \mathrm{C}\right)\end{array}$ & $\begin{array}{c}\text { Number of } \\
\text { days in T1 } \\
\text { medium }^{\mathrm{a}}\end{array}$ & $\begin{array}{c}\text { Number of } \\
\text { days with P } \\
\text { medium }^{\mathrm{b}}\end{array}$ & $\begin{array}{c}\text { Germination } \\
\text { percentage } \\
(\text { Mean } \pm \mathrm{SE})^{\mathrm{c}}\end{array}$ \\
\hline Late uninucleate & 25 & 4 & 2 & $69.2 \pm 7.9$ \\
Early binucleate & 25 & 3 & 2 & $13.3 \pm 1.5$ \\
& 20 & 3 & 2 & $3.6 \pm 0.5$ \\
& 25 & 2 & 2 & $60.5 \pm 3.3$ \\
\hline
\end{tabular}

a Number of days cultured in $1 \mathrm{ml} \mathrm{T1}$ medium; ${ }^{\mathrm{b}}$ Number of days in culture after $\mathrm{T} 1$ medium was supplemented with $1 \mathrm{ml} \mathrm{P}$ medium each day; 'Mean of observations taken from three different culture plates \pm standard error.

Touraev and Heberle-Bors (1999) reported that, depending on the developmental stage and synchrony of the starting population (ratio of unicellular to early-bicellular microspores), the incubation time in T1 medium required for maturation can vary from three to four days. In our experiments, four days of culture in $\mathrm{T} 1$ yielded the higher germination frequency $(\sim 70 \%)$ for late-uninucleate microspores (Table 1). Shortening the culture duration in T1 medium to three days for early uninucleate microspore reduced the germination frequency while four days culture of early binucleate pollen at $25^{\circ} \mathrm{C}$ resulted in over maturation and subsequent rupture of the cells. Reduction of culture 
duration for binucleate pollen improved the germination frequency $(\sim 30 \%)$ but not to the same level achieved with late-uninucleate microspores. The highest germination frequency $(>60 \%)$ for the early-binucleate pollen was achieved when the culture temperature was reduced to $20^{\circ} \mathrm{C}$. This was observed under a culture regime of three days in T1 medium accompanied by two days of supplementation with P medium each day. This culture combination was used in all subsequent experiments for the maturation of early-binucleate pollen. The time required for in vitro maturation was similar to that required for maturation in vivo under glasshouse conditions. Control by temperature regulation of the duration of in vitro microspore maturation may be useful in future studies of gene expression and pollen development.

Choice of plasmid vectors: Transient gene expression requires a gene product that can be easily and rapidly monitored (Southgate et al. 1995). The GUS reporter system has been used successfully for tobacco microspore transformation previously (Aziz and Machray 2003; Barinova et al. 2002, Touraev et al. 1997). To circumvent the cytotoxic problem associated with the GUS reporter system, the GFP gene has been successfully used for screening transformed barley microspores (Carlson et al. 2001) and to study transient gene expression of microprojectile-bombarded Antirrhinum majus (Barinova et al. 2002) and Brassica napus L. (Nehlin et al. 2000) microspores. The advantage of using GFP is that it is a non-toxic fluorescent reporter and does not require any exogenous substrates or co-factors for fluorescence, allowing real-time monitoring of its expression. Moreover, the ability of GFP to emit green fluorescence is preserved in N-terminal or C-terminal fusion proteins making it an ideal reporter system for the study of gene expression and function (Bellucci et al. 2003).

Another important component in the vector construction is the promoter to drive the expression of the introduced genes. The CaMV 35S promoter effectively drives expression of a downstream gene, escaping regulatory control by the host genome (Yoo et al. 2005). This promoter has been extensively used with various degrees of success in many plant species and tissues. Previously this promoter has successfully been used to express uidA (GUS), gfp, and hygromycinresistance (hpt) genes in microspores (Aziz and Machray 2003, Kasha et al. 2001, Touraev et al. 1997). Some authors have observed very low to no expression of biolistically-delivered genes in pollen when driven by a CaMV 355 promoter (Hamilton et al. 1998, Eyal et al. 1995, Twell et al. 1989). However, previous work using two pollen specific promoters did not consistently show any significant improvement over 35S, especially with GFP and RFP (Barinova et al. 2002). The $35 \mathrm{~S}$ promoter includes a strong enhancer sequence (Benfey et al. 1990a, Benfey et al. 1990b) which can even trans activate genes away from the 
integration site (Yoo et al. 2005). In order to increase the possibility of strong transient expression of the reporter gene, we chose the construct based on the plasmid pRTL2 with CaMV 35S promoter having a dual enhancer sequence followed by a translational enhancer sequence from Tobacco Etch Virus (TEV) to drive the $m G F P 5-E R$ gene which was codon optimised and modified for its optimal expression in plant tissues (Hasseloff et al. 1997, Siemering et al. 1996) producing a stable version of the protein localised in the endoplasmic reticulum (ER).

Transient expression after bombardment of microspores: The amount of DNA delivered into the cell is an important factor for efficient transformation. Increasing the concentration of DNA to coat the microprojectiles should theoretically increase the transformation frequency in a linear manner. However, high dosages of DNA have been shown to result in aggregation of the microprojectiles, reducing transformation frequencies. (Oard 1991). Consequently, it is important to employ a DNA concentration that combines minimum particle aggregation with maximum potential transformation efficiency (Southgate et al. 1995).

Table 2. Effect of DNA concentration on maturation and GFP expression after bombardment of early-binucleate pollen with various amounts of pRTL2mGFP5-ER plasmid and $3 \mathrm{mg} / \mathrm{shot}$ gold.

\begin{tabular}{lcc}
\hline $\begin{array}{l}\text { DNA conc. } \\
(\mu \mathrm{g} / \text { shot })\end{array}$ & $\begin{array}{c}\text { Maturation \% } \\
(\text { Mean } \pm S E)^{\mathrm{a}}\end{array}$ & $\begin{array}{c}\text { \% GFP expression } \\
(\text { Mean } \pm \mathrm{SE})^{\mathrm{a}}\end{array}$ \\
\hline Non-bombarded & $71.5 \pm 8.6$ & 0 \\
2.5 & $32.2 \pm 2.3$ & $2.7 \pm 0.4$ \\
5.0 & $37.1 \pm 1.6$ & $5.7 \pm 0.1$ \\
10.0 & $30.7 \pm 5.6$ & $10.6 \pm 0.6$ \\
15.0 & $32.2 \pm 2.1$ & $4.8 \pm 0.6$ \\
\hline
\end{tabular}

${ }^{a}$ Mean of observations taken from three different culture plates \pm standard error. Maturation percentage - as per cent of total cells counted which matured; GFP expression - as per cent of matured pollen expressing GFP.

Several concentrations of the plasmid pRTL2mGFP5-ER were used in the first experiment for bombardment of early-binucleate pollen keeping the gold concentration constant $(3.0 \mathrm{mg} / \mathrm{shot})$. While maturation percentages were similar in all bombarded samples, the highest level $(>10 \%)$ of GFP expression was obtained at a concentration of $10 \mu \mathrm{g}$ of DNA was used (Table 2). However, a lower frequency of expression ( $4 \%$ ) was observed in pollen (arrowed in Fig. 2A) after 6 days of maturation. Higher amounts of DNA caused visible clumping of the particles similar to that reported by Oard (1991). Other studies have also shown that varying the amount of gold and DNA and the DNA/gold preparation procedure have a significant effect on the transient expression of GUS gene and 
also on the variability of gene expression between individual shots (Harwood et al. 2000). Barinova et al. (2002) also observed differences in transient gene expression among different gene constructs in Antirrhinum male gametic cells.

Previous studies have indicated that the frequency of transient expression increases gradually over several days after bombardment and then decreases after reaching a peak. In barley microspores, the transient expression of GFP was detectable as a faint-green fluorescence within $2 \mathrm{hr}$ of bombardment. Between two and three days after bombardment the number of fluorescing microspores reached a maximum; at 14 day post-bombardment the number declined to about $5 \%$ of the maximum number observed (Carlson et al. 2001). Barinova et al. (2002) observed a twofold reduction in the transient expression in bombarded Antirrhinum microspores during in vitro maturation over eight days.
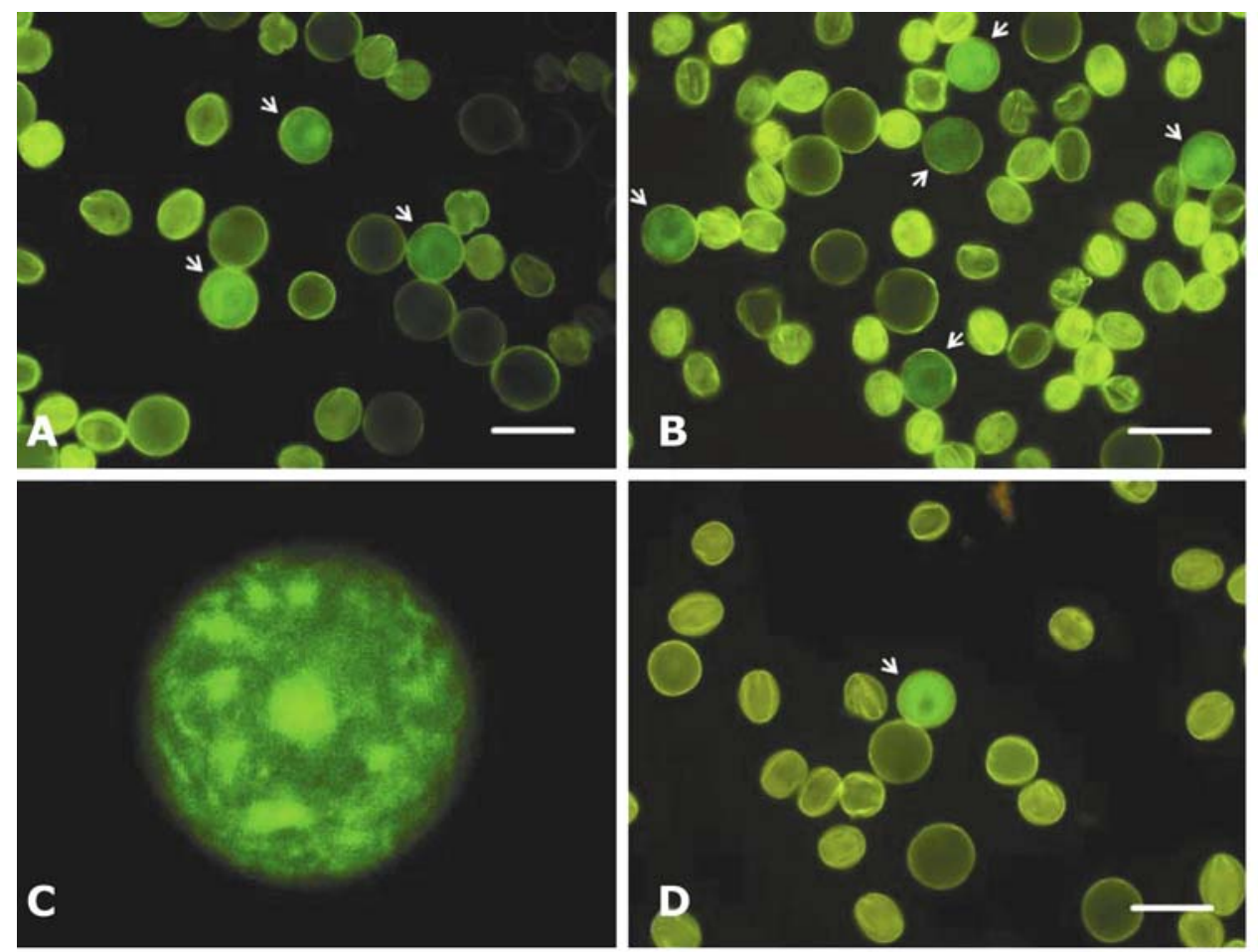

Fig. 2. Transient expression (arrowed) of $m G F P 5-E R$ gene in in vitro matured pollen bombarded at late-uninucleate (A) and early-binucleate stage (B). A confocal photomicrograph showing localisation of GFP in the ER (C). GFP expression in in vitro matured pollen co-bombarded at early-binucleate stage with two non-functional versions of the $m$ GFP5-ER gene (D). Smaller elliptical structures fluorescing bright are microspores which did not mature. Bar $\sim 50 \mu \mathrm{m}$. 
In the second experiment, both uni- and binucleate microspores were bombarded with pRTL2mGFP5-ER DNA and observations were taken every day from an aliquot of the bombarded cells. After one day of bombardment only sporadic expression was observed in both uni- and binucleate microspores: binucleate microspores showing a marginally higher expression level. Expression in uninucleate cells continued to be low, reaching a peak $(2.8 \pm 0.9 \%)$ Five - six days after bombardment, later dropping again to sporadic (a few cells per plate) level. In binucleate pollen, the expression level started to increase from the 2nd day after bombardment reaching its peak $(9.5 \pm 0.1 \%)$ on days four - five (arrowed in Fig. 2B) before decreasing again. The $m$ GFP5-ER gene used in these experiments contains an $\mathrm{N}$-terminal signal peptide derived from an Arabidopsis vacuolar basic chitinase and the $\mathrm{C}$-terminal amino acid sequence HDEL to ensure secretion and retention of the gene product within the lumen of the (ER. A detailed study with laser-scanning confocal microscopy revealed that the GFP expression was consistent with the localization in the ER (Fig. 2C).

Extra chromosomal recombination of plasmid DNA after delivery: Based on the highest gene expression in the previous experiments, we designed an experiment to study whether the haploid phase of higher plants can increase the HR efficiency. Previously, deletion mapping of GFP expression constructs revealed that amino acid (aa) residues 2 - 232 of a total of 238 aa in the native protein were required for the characteristic emission and absorption spectra of native GFP (Dopf and Horiagon 1996). Two mutant versions of the mGFP5-ER gene were generated by incorporating three contiguous stop codons either at the beginning or at the end of the coding region (within the reported disruption zone for the native $g f p$ gene) to render the genes non-functional (Fig. 1). The $m G F P 5-E R$ is a modified version of the native gene with 264 aa residues including sequences that code for ER localization signal peptides (Hasseloff et al. 1997). Hence the functionality of the mutant versions of the gene was studied in the tobacco protoplast transient expression system along with the non-mutated functional version of the gene as control.

Twenty-four hours after transfection with the plasmids, GFP fluorescence localized on the ER was observed only in protoplasts with the functional version of the plasmid but not with either of the mutated versions indicating that the introduced stop codons at either end of the gene are sufficient for its loss of function. RNA from the transfected protoplasts was isolated and sequencespecific amplification products were generated by RT-PCR (data not shown) for the $m G F P 5-E R$ gene as well as for the two non-functional ones. The mutated genes were transcribed to mRNA but no functional protein was produced at translation due to the presence of the inserted stop codons. 
Early-binucleate pollen were bombarded with the functional pRTL2mGFP5ER plasmid, the two non-functional versions independently and also cobombarded with the two non-functional versions. Any GFP fluorescence observed in the co-bombarded microspores could signal a recombination event between the two non-functional plasmids. No GFP expression was detected after a five-day maturation period in microspores bombarded with the mutated nonfunctional versions of the gene compared to $19.5 \%$ expression with the functional one (Table 3).

Table 3. In vitro maturation and gene expression in early-binucleate pollen bombarded with plasmids containing different versions of $m G F P 5-E R$ gene.

\begin{tabular}{lcl}
\hline $\begin{array}{l}\text { Plasmid used for } \\
\text { bombardment }\end{array}$ & $\begin{array}{c}\text { Maturation percentage } \\
(\text { Mean } \pm \text { SE) }\end{array}$ & $\begin{array}{l}\text { Percentage of GFP } \\
\text { expression (Mean } \pm \text { SE) }\end{array}$ \\
\hline Control without bombardment & $51.7 \pm 0.8$ & $0^{c}$ \\
pRTL2mGFP5-ER & $10.4 \pm 1.1$ & $19.5 \pm 0.1^{\mathrm{b}}$ \\
pRTL2M1mGFP5-ER & $16.7 \pm 2.8$ & $0^{c}$ \\
pRTL2M2mGFP5-ER & $13.8 \pm 0.8$ & $0^{c}$ \\
Co-bombarded with & $13.8 \pm 3.2$ & 2 pollen out of $~ 10^{6}$ \\
pRTL2M1mGFP5-ER + & & $\begin{array}{l}\text { bombarded pollen }(4 \\
\text { flower buds) }\end{array}$ \\
\hline
\end{tabular}

aMaturation percentage- as per cent of total cells which matured; mean of observations taken from three different culture plates \pm standard error. ${ }^{b}$ GFP expression- as per cent of matured pollen expressing GFP; mean of observations taken from three different culture plates \pm standard error. ${ }^{c}$ Observation taken from all bombarded cells.

Only two fluorescent pollen grains were detected (Fig. 2D) among the cobombarded pollen from a total of four flower buds ( $10^{6}$ pollen grains) indicating that recombination did occur between the two non-functional plasmids inside the maturing microspores. This frequency is, however, low, similar or lower than the extrachromosomal recombination frequency observed previously in somatic cells (De Groot et al. 1992, Baur et al. 1990, Offringa et al. 1990). In the present study the overall transient expression of the delivered GFP gene in the uninucleate microspores was slightly over $4 \%$ whereas, in case of binucleate pollen the frequency ranged from 10 and $20 \%$. This number is much higher than that reported before (Barinova et al. 2002, Carlson et al. 2001). Optimization of DNA delivery and the use of a CaMV 35S promoter with a dual enhancer in combination with a TEV translational enhancer sequence might have contributed to this high expression (Carrington and Freed 1990). Some variations were observed between the experiments during the course of this study. However, similar fluctuations in transformation efficiency were observed previously from 
day to day and month-to-month and also from one microcentrifuge tube (i.e. precipitation event) to another (Sanford et al. 1993).

Use of the non-lethal GFP reporter gene allowed observation of transgene expression during microspore maturation, which in the future might also be used for pollen selection. The protocol described here could be used to study developmental stage-specific gene expression in pollen by isolating male gametic cells and delivering DNA into them at various stages of development under controlled conditions. However, using male gametophytes as the haploid equivalent in higher plants, no increase of extrachromosomal recombination was observed in assays for transient transformation indicating that the haploid state itself may not be the sole factor influencing HR.

\section{Acknowledgements}

This study was supported by the Scottish Executive Environment and Rural Affairs Department. M.A.Y. Akhond thanks Scottish Crop Research Institute (SCRI) and MRS Ltd. for their support.

\section{References}

Alché JD, M'rani-Alaoui M, Castro AJ and Rodríguez-García MI (2004) Ole e 1, the major allergen from olive (Olea europaea L.) pollen, increases its expression and is released to the culture medium during in vitro germination. Plant and Cell Physiol. 45: 1149-1157.

Aziz N and Machray GC (2003) Efficient male germ line transformation for transgenic tobacco production without selection. Plant Mol. Biol. 51: 203-211.

Barinova I, Zhexembekova M, Barsova E, Lukyanov S, Heberle-Bors, E and Touraev A (2002) Antirrhinum majus microspore maturation and transient transformation in vitro. J. Exp. Bot. 53: 1119-1129.

Bate N and Twell D (1998) Functional architecture of a late pollen promoter: pollenspecific transcription is developmentally regulated by multiple stage-specific and codependent activator elements. Plant Mol. Biol. 37: 859-869.

Baur M, Potrykus I and Paszkowski J (1990) Intermolecular homologous recombination in plants. Mol. Cell Biol. 10: 492-500.

Becker JD, Boavida LC, Carneiro J, Haury M and Feijó JA (2003) Transcriptional profiling of Arabidopsis tissues reveals the unique characteristics of the pollen transcriptome. Plant Physiol. 133: 713-725.

Bellucci M, De Marchis F, Mannucci R and Arcioni S (2003) Jellyfish green fluorescent protein as a useful reporter for transient expression and stable transformation in Medicago sativa L. Plant Cell Rep. 22: 328-337.

Benfey PN, Ren L and Chua N-H (1990a) Tissue-specific expression from CaMV 35 S enhancer subdomains in early stages of plant development. EMBO J. 9(6): 1677-1684.

Benfey PN, Ren L and Chua N-H (1990b) Combinatorial and synergistic properties of CaMV $35 S$ enhancer subdomains. EMBO J. 9(6): 1685-1696. 
Benito Moreno RM, Macke F, Alwen A and Heberle-Bors E (1988) In-situ seed production after pollination with in-vitro-matured, isolated pollen. Planta. 176: 145148.

Carlson AR, Letarte J, Chen J and Kasha KJ (2001) Visual screening of microsporederived transgenic barley (Hordeum vulgare L.) with green-fluorescenct protein. Plant Cell Rep. 20: 331-337.

Carrington JC and Freed DD (1990) Cap-independent enhancement of translation by a plant potyvirus 5' nontranslated region. J. Virology. 64(4): 1590-1597.

De Groot MJA, Offringa R, Does MP, Hooykaas PJJ and Van den Elzen PJM (1992) Mechanisms of intermolecular homologous recombination in plants as studied with single- and double-stranded DNA molecules. Nucleic Acids Res. 20: 2785-2794.

Dopf J and Horiagon T (1996) Deletion mapping of the Aequorea victoria green fluorescent protein. Gene 173: 39-44.

Eyal Y, Curie C and McCormick S (1995) Pollen specificity elements reside in 30 bp of the proximal promoters of two pollen-expressed genes. The Plant Cell. 7: 373-384.

Hamilton DA, Roy M, Rueda J, Sindhu RK, Sanford J and Mascarenhas JP (1992) Dissection of a pollen-specific promoter from maize by transient transformation assays. Plant Mol. Biol. 18: 211-218.

Hamilton DA, Schwarz YH and Mascarenhas JP (1998) A monocot. pollen-specific promoter contains separable pollen-specific and quantitative elements. Plant Mol. Biol. 38: 663-669.

Hanin M, Volrath S, Bogucki A, Briker M, Ward E and Paszkowski J (2001) Gene targeting in Arabidopsis. Plant J. 28: 671-677.

Harwood WA, Ross SM, Cliento P and Snape JW (2000) The effect of DNA/gold particle preparation technique, and particle bombardment device, on the transformation of barley (Hordeum vulgare). Euphytica 111: 67-76.

Haseloff J, Siemering KR, Prasher DC and Hodge S (1997) Removal of a cryptic intron and subcellular localisation of green fluorescent protein are required to mark transgenic Arabidopsis plants brightly. Proc. Nat. Acad. Sci. 94: 2122-2127.

Honys D and Twell D (2003) Comparative analysis of the Arabidopsis pollen transcriptome. Plant Physiol. 132: 640-652.

Hrubá P, Honys D, Twell D, Čapková V and Tupý J (2005) Expression of $\beta$-galactosidase and $\beta$-xylosidase genes during microspore and pollen development. Planta 220: 931940.

Kasha KJ, Simion E, Oro R, Yao QA, Hu TC and Carlson AR (2001) An improved in vitro technique for isolated microspore culture of barley. Euphytica 120: 379-385.

Kyo M and Harada H (1986) Control of the developmental pathway of tobacco pollen in vitro. Planta 168: 427-432.

Mascarenhas JP (1990) Gene activity during pollen development. Annual Rev Plant Physiol Plant Mol. Biol. 41: 317-338.

Nehlin L, Möllers C, Bergman P and Glimelius K (2000) Transient $\beta$-gus and gfp gene expression and viability analysis of microprojectile bombarded microspores of Brassica napus L. Plant Physiol. 156: 175-183. 
Oard J (1991) Physical methods for the transformation of plant cells. Biotech. Adv. 9: 1-11.

Offringa R, De Groot JA, Haagsman HJ, Does MP, Van den Elzen PJM and Hooykaas PJJ (1990) Extrachromosomal homologous recombination and gene targeting in plant cells after Agrobacterium-mediated transformation. EMBO J. 9: 3077-3084.

Sanford JC, Smith FD and Russell JA (1993) Optimizing the biolistic process for different biological applications. Methods in Enzymology. 217: 483-509.

Schaefer DG (2001) Gene targeting in Physcomitrella patens. Curr Opinion Plant Biol. 4: 138-141.

Schaefer DG and Zrÿd J-P (1997) Efficient gene targeting in the moss Physcomitrella patens. Plant J. 11: 1195-1206.

Schreiber DN and Dresselhaus T (2003) In vitro pollen germination and transient transformation of Zea mays and other plant species. Plant Mol. Biol. Reporter 21: 3141.

Siemering KR, Golbik R, Sever R and Haseloff J (1996) Mutations that suppress the thermosensitivity of green fluorescent protein. Curr. Biol. 6: 1653-1663.

Simpson CG, Clark GP, Davidson D, Smith P and Brown JWS (1996) Mutation of putative branchpoint consensus sequences in plant introns reduces splicing efficiency. Plant J. 9: 369-380.

Simpson CG, Hedley PE, Watters JA, Clark GP, McQuade C, Machray GC and Brown JWS (2000) Requirements for mini-exon inclusion in potato invertase mRNAs provides evidence for exon-scanning in plants. RNA 6: 422-433.

Southgate EM, Davey MR, Power JB and Marchant R (1995) Factors affecting the genetic engineering of plants by microprojectile bombardment. Biotech. Adv. 13: 631-651.

Stauffer C, Benito Moreno RM and Heberle-Bors E (1991) In situ pollination with in vitro matured pollen of Triticum aestivum. Theor. Appl. Genet. 81: 576-580.

Terada R, Urawa H, Inagaki Y, Tsugane K and Iida S (2002) Efficient gene targeting by homologous recombination in rice. Nat. Biotech. 20: 1030-1034.

Touraev A and Heberle-Bors E (1999) Microspore Embryogenesis and In Vitro Pollen Maturation in Tobacco. In: Hall RD (Ed) Plant Cell Culture Protocols, Vol. 111. Totowa, NJ: Humana Press Inc. 281-292.

Touraev A, Stöger E, Voronin V and Heberle-Bors E (1997) Plant male germ line transformation. Plant J. 12: 949-958.

Tupý J, Rihová L and Zárský V (1991) Production of fertile tobacco pollen from microspores in suspension culture and its storage for in situ pollination. Sex Plant Reprod. 4: 284-287.

Twell D (1994) The diversity and regulation of gene expression in the pathway of male gametophyte development. In: Scott RJ, Stead AD (Eds) Molecular and Cellular Aspects of Plant Reproduction, Cambridge, UK: Cambridge University Press, 83-115.

Twell D (2002) The developmental biology of pollen. In: Roberts JA (Ed) Plant Reproduction Vol 6. Sheffield, UK: Sheffield Academic Press, 86-153.

Twell D, Klein TM, Fromm ME and McCormick S (1989) Transient expression of chimeric genes delivered into pollen by microprojectile bombardment. Plant Physiol. 91: $1270-1274$. 
Vergne P, Delvallee I and Dumas C (1987) Rapid assessment of microspore and pollen development stage in wheat and maize using DAPI and membrane permeabilization. Stain Techn. 62: 299-304.

Yoo SY, Bomblies K, Yoo SK, Yang JW, Choi MS, Lee JS, Weigel D and Ahn JH (2005) The $35 \mathrm{~S}$ promoter used in a selectable marker gene of a plant transformation vector affects the expression of the transgene. Planta 221: 523-530. 